\title{
Exportações estaduais no Brasil: estimativas para as elasticidades preço e renda
}

\author{
ANA CRISTINA PEREIRA DAS NEVES \\ MARCOS TADEU CAPUTI LÉLIS*
}

State exports in Brazil: estimates of price and income elasticities. This paper analyses the recent performance of Brazilian exports, based on estimates of price and income elasticities of states external sellings. After presenting an overview of the national position, the aim is to check if, by exporting dynamic goods of high value, some of them were able to achieve an external position different from Brazilian's. Nevertheless, the results, as the ones obtained by other empirical works, indicate that all but one states have inelastic exports with respect to both prices and income.

Key-words: Brazilian economy, state exports; elasticities.

JEL Classification: C33; F10; E00

\section{INTRODUÇÃO}

No Brasil, ao contrário de outros países em desenvolvimento, as exportações não representam grande parcela no total da renda. ${ }^{1}$ Ainda assim, por serem um componente autônomo de gasto (cujo comportamento depende, entre outros fatores, dos preços e do poder de compra dos demandantes) elas podem, através da ação do multiplicador keynesiano, ter efeitos expansivos sobre a atividade doméstica. Isso significa que, apesar de não representarem parcela elevada do PIB, as exportações podem cumprir, no caso brasileiro, o importante papel de permitirem o relaxamento da restrição externa ao crescimento, possibilitando que se

\footnotetext{
* Respectivamente, Mestre pelo Instituto de Economia da UFRJ (E-mail: acpneves@yahoo.com.br)e doutorando em economia pelo PPGE UFRGS e Bolsista do CNPq. (E-mail: mcaputi@uol.com.br). Os autores agradecem aos professores Hélio Migon e Nelson Barbosa Filho e ao Grupo de Conjuntura do IE/UFRJ pelos comentários e apoio na elaboração do artigo. Valem as observações habituais quanto aos erros e problemas que por ventura persistam. Submetido: junho 2004; Aceio fevereiro 2006.

${ }^{1}$ Em 2002, a participação das exportações no PIB chileno era de mais de 30\% (a preços correntes), enquanto no Brasil, se situava em torno dos $15 \%$.
} 
efetivem as importações necessárias a ele. Portanto, ainda que, enquanto componente autônomo da demanda efetiva, as exportações tenham importância limitada, são fundamentais para "o equacionamento do financiamento externo do desenvolvimento econômico" (Medeiros e Serrano, 2001:2), especialmente em momentos de desaceleração, quando as entradas de recursos externos diminuem e a saída de capitais aumenta.

Dessa forma, é relevante estudar o comportamento das exportações, procurando estimar suas elasticidades de preço e renda, e buscando verificar qual tipo de relação apresentam. ${ }^{2}$ Trabalhos empíricos anteriores sugerem um comportamento inelástico das exportações brasileiras tanto em relação aos preços (câmbio real) quanto à demanda internacional - isso porque produtos de baixo valor agregado ainda possuem participação expressiva na pauta de exportação do país.

Tendo como base o panorama das vendas externas do Brasil, é interessante procurar examinar qual a contribuição dos diversos estados para tal comportamento agregado, buscando verificar se algum deles apresenta uma dinâmica que o diferencie da do país - e, portanto, esteja mais próxima à dos países com pautas de exportação em que produtos de alto valor agregado são os mais relevantes.

O objetivo deste artigo, que está estruturado em cinco seções além desta introdução, é exatamente estimar e discutir as elasticidades preço e renda das exportações dos estados brasileiros. Na seção dois, discute-se o desenvolvimento recente das vendas externas brasileiras. Em seguida, após breve apresentação das fontes de dados e seu tratamento, são expostos, na quarta seção, os dois modelos com os quais trabalhamos. Os resultados econométricos são apresentados e analisados na seção cinco, na qual também são destacadas algumas especificidades locais. Finalmente, na conclusão, são retomados os resultados mais importantes, destacados os casos de alguns dos principais estados exportadores e enfatizadas as fragilidades da inserção exportadora brasileira no período analisado.

\section{DETERMINANTES DAS EXPORTAÇÕES E O CASO BRASILEIRO}

Em um primeiro corte, os fatores que determinam as exportações podem ser classificados em duas categorias: os estruturais e os conjunturais. Os primeiros abrangem localização geográfica, dotação de recursos naturais, instituições locais, infra-estrutura, entre outros. O caso do Rio de Janeiro é exemplar: o estado é o quinto maior exportador do Brasil, e o capítulo de óleos e combustíveis minerais representou $40 \%$ de suas exportações e $63 \%$ das exportações brasileiras desses produtos em 2004, indicando que a dotação de recursos naturais é fundamental para o desempenho do estado.

\footnotetext{
${ }^{2}$ Existem três conceitos de elasticidade de exportações: 1) de impacto, que mede a resposta das exportações nos seis primeiros meses após a mudança na variável exógena (por ex., câmbio); 2) de curto prazo, que se refere ao ajuste após um ano; e 3) de longo prazo, que capta a resposta após um longo período (ver Krugman e Obstfeld, 2001:cap. 16). É essa última o foco deste trabalho.
} 
Os fatores conjunturais se referem, principalmente, a duas variáveis: a renda internacional alocada ao consumo de tradables e a relação entre preços domésticos e externos (preço relativo). Nos estudos sobre comércio exterior comumente se usam, como proxy para renda internacional, as importações mundiais, incorporando à análise somente a parcela da renda que se refere especificamente ao comércio mundial. A variável de preço escolhida, por sua vez, geralmente considera tanto preços internacionais de tradables de forma ampla, como preços relevantes para parceiros comerciais do país em estudo (Cavalcanti e Ribeiro, 1998). Neste trabalho, optou-se por utilizar as importações mundiais e o câmbio real efetivo, que incorpora diferenças nos preços relativos.

Outras variáveis explicativas muitas vezes utilizadas se relacionam ao nível de atividade interna. Um bom indicador para ela é o grau de utilização da capacidade instalada na indústria, variável escolhida neste trabalho.

Uma análise preliminar dos dados permite algumas inferências sobre o comportamento das exportações brasileiras e suas relações com as variáveis escolhidas. O gráfico 1 apresenta o crescimento das importações mundiais e das exportações brasileiras no período de 1992 a 2004, permitindo observar, de modo geral, duas dinâmicas distintas. A primeira refere-se ao desempenho inferior das vendas internacionais do país durante o período que se inicia em 1994 e estende-se até 2000. Já em 2001, observa-se uma queda nas importações mundiais e um contínuo crescimento das vendas externas brasileiras, iniciando-se um período onde o índice de crescimento das exportações do Brasil é relativamente mais elevado que o atingido pelas importações mundiais. No entanto, os anos de 2003 e 2004 já apresentam uma aceleração maior nesse último agregado e, como resultado, a taxa de crescimento das duas variáveis, no período completo, é praticamente igual.

Gráfico 1: Índice das Exportações Brasileiras e das Importações Mundiais,

US\$ FOB constantes de $1998(1992=100)$

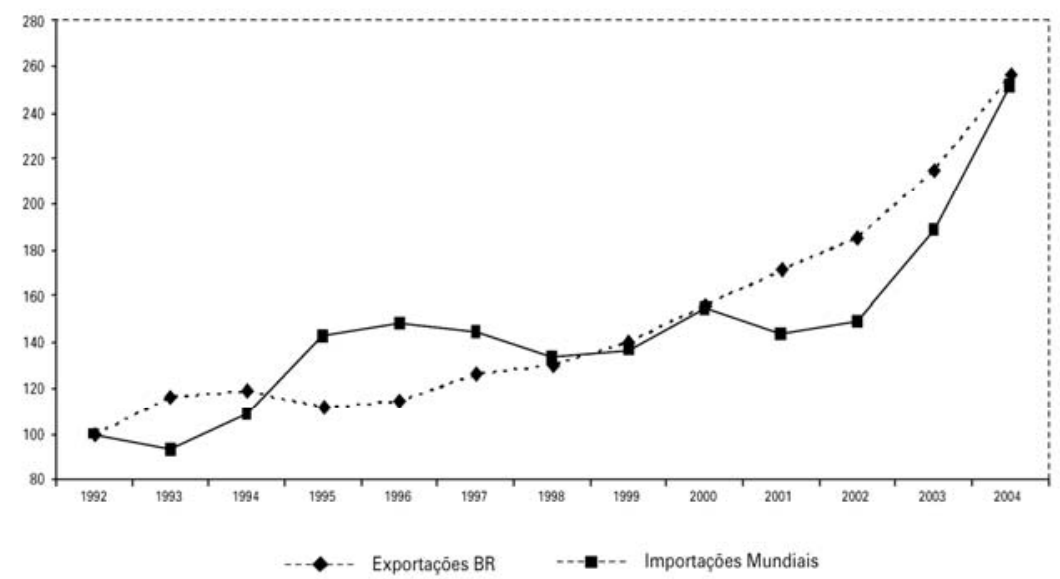

Fonte: Ministério do Desenvolvimento, Indústria e Comércio. 
Os principais responsáveis pela melhora recente nas vendas do país foram os produtos básicos, que apresentaram grande crescimento entre 2001 e 2004 $(98 \%)$ e aumentaram sua participação no total das exportações, que passou de $26,1 \%$ para $29,7 \%$ (gráfico 2 e tabela 1 ).

O único momento de queda nas exportações (a valores constantes) ocorreu entre 1994 e 1995, como decorrência da mudança de regime cambial. Com a estabilização e a valorização do real, as exportações caíram 6,6\%, sendo os manufaturados os principais responsáveis por essa retração (sofreram queda de $11 \%$ ). Somente os semi-manufaturados foram capazes de apresentar algum dinamismo nesse ano, crescendo $7,2 \%$, o que, porém, não foi suficiente para compensar a diminuição dos outros tipos de produtos, dada sua baixa participação na pauta brasileira (16,9\% em 1995, conforme tabela 1$)$.

A partir de 2001, as vendas externas do país apresentaram crescimento consistente de 13,2\% a.a. em média, contra 4,7\% a.a. no período entre 1995 e 2000, o que possibilitou a recuperação das perdas relativas sofridas no início da década.

Gráfico 2: Índice das Exportações Brasileiras por Fator Agregado, ${ }^{3}$

US\$ FOB constantes de $1998(1992=100)$

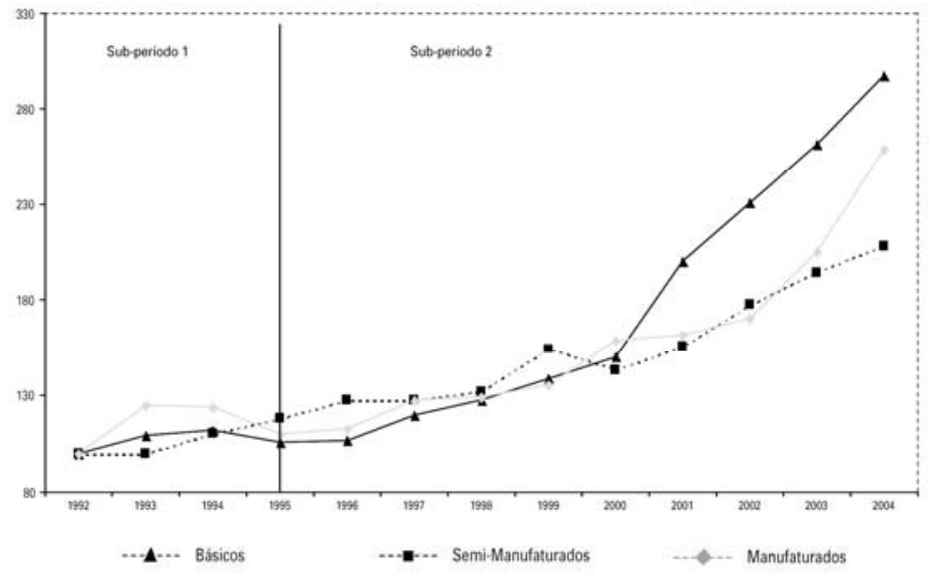

Fonte: Ministério do Desenvolvimento, Comércio e Indústria.

O contínuo crescimento das exportações entre 1995 e 2004 resultou de um desempenho médio diferenciado entre básicos e manufaturados $(13,8 \%$ a.a. e $11,9 \%$ a.a., respectivamente), que, juntos, correspondiam, em 2004, a $87,4 \%$ do total exportado.

É importante ressaltar que, nos últimos cinco anos do período, o aumento de mais de $4 \%$ na participação dos básicos nas exportações totais foi acompanhado por uma queda de magnitude próxima a $2 \%$ nas vendas de manufatura-

${ }^{3}$ Entenda-se por fator agregado a distinção enre produtos básicos manufaturados e semimanufaturados. 
dos (ver tabela 1, preços constantes), evidenciando uma maior relevância na pauta de exportações brasileiras de produtos cujo dinamismo é determinado pela relação entre oferta e demanda no mercado internacional, sem ingerência direta do produtor local sobre os preços. Na medida em que no caso das commodities, não há diferenciação de produtos, incrementos na produção tendem a reduzir os preços, contrabalançando possíveis ganhos de um maior volume exportado.

Tabela 1: Decomposição das Exportações Brasileiras por Fator Agregado

(\%, US\$ correntes e constantes de 1998)

\begin{tabular}{lcccccc}
\hline & \multicolumn{2}{c}{ Básicos } & \multicolumn{2}{c}{ Semi-manufaturados } & \multicolumn{2}{c}{ Manufaturados } \\
\hline $\begin{array}{c}\text { US\$ } \\
\text { correntes }\end{array}$ & $\begin{array}{c}\text { US\$ } \\
\text { constantes }\end{array}$ & $\begin{array}{c}\text { US\$ } \\
\text { correntes }\end{array}$ & $\begin{array}{c}\text { US } \\
\text { constantes }\end{array}$ & $\begin{array}{c}\text { US\$ } \\
\text { correntes }\end{array}$ & $\begin{array}{c}\text { US\$ } \\
\text { constantes }\end{array}$ \\
\hline 1992 & 25,0 & 26,1 & 16,3 & 15,8 & 58,7 & 58,1 \\
\hline 1993 & 24,5 & 24,3 & 14,2 & 13,5 & 61,3 & 62,2 \\
\hline 1994 & 25,8 & 24,6 & 16,1 & 14,7 & 58,2 & 60,7 \\
\hline 1996 & 24,0 & 25,1 & 20,0 & 16,9 & 56,0 & 58,0 \\
\hline 1997 & 25,4 & 24,4 & 18,4 & 17,7 & 56,3 & 57,8 \\
\hline 1998 & 27,8 & 24,9 & 16,3 & 16,1 & 56,0 & 59,0 \\
\hline 1999 & 25,7 & 25,7 & 16,1 & 16,1 & 58,2 & 58,2 \\
\hline 2000 & 23,1 & 26,0 & 16,9 & 17,5 & 58,0 & 56,5 \\
\hline 2001 & 27,2 & 25,5 & 15,9 & 14,7 & 60,7 & 59,8 \\
\hline 2002 & 28,8 & 32,2 & 15,2 & 14,9 & 56,0 & 55,0 \\
\hline 2003 & 29,5 & 31,3 & 15,2 & 14,1 & 55,2 & 52,9 \\
\hline 2004 & 30,1 & 29,7 & 14,2 & 12,6 & 55,8 & 57,7 \\
\hline
\end{tabular}

Fonte: Ministério do Desenvolvimento, Comércio e Indústria.

O gráfico 3 permite estabelecermos algumas relações entre o comportamento das exportações e o movimento de preços e câmbio real, variáveis representativas da rentabilidade das vendas externas. O período analisado pode ser dividido em três sub-períodos. O primeiro deles corresponde aos anos de 1992 a 1994, quando as três variáveis se comportaram de forma estável. O segundo sub-período, que compreende os anos entre 1994 e 1998, se iniciou com valorização da moeda nacional, subida dos preços e queda das exportações, provavelmente devido ao comportamento do câmbio e dos preços, e ao aquecimento da economia nacional. Nos anos seguintes observou-se estabilidade cambial, leve aumento das exportações e preços situados nos maiores patamares de todo o período analisado, iniciando movimento de queda apenas em 1998. Finalmente, no último subperíodo, houve forte depreciação da moeda, aumentando a rentabilidade do exportador, e queda dos preços seguida de relativa estabilidade (com leve recuperação ao final). Essa combinação de fatores estimulou as exportações tanto pelo lado do ofertante quanto pelo do demandante, resultando em aumento de $11,9 \%$ a.a. em média, entre 1999 e 2004. 
Gráfico 3: Índices das Exportações (em US\$ FOB constantes de 1998), dos Preços das Exportações e do Câmbio Real Brasileiro (1992 = 100)

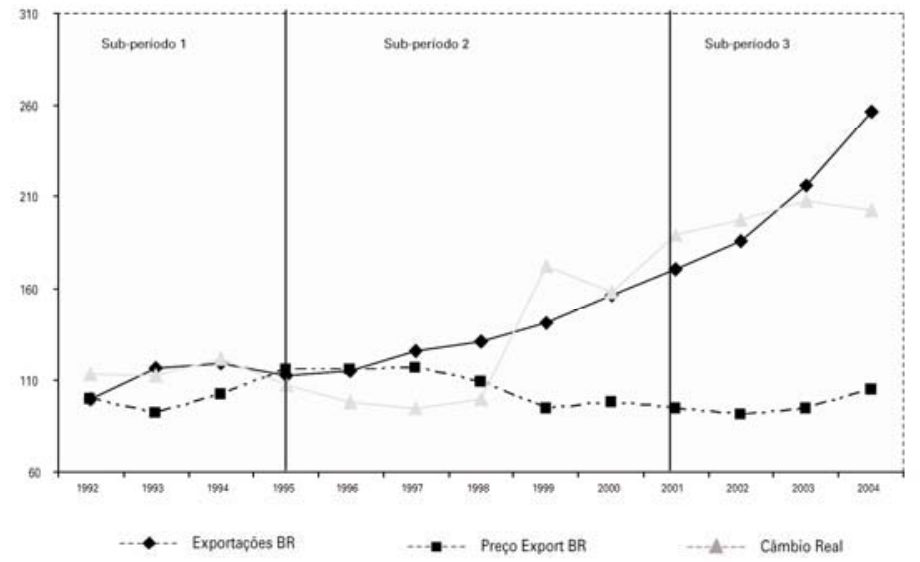

Fontes: MDIC, FUNCEX e Grupo de Conjuntura do Instituto de Economia da UFRJ

Se analisarmos os preços das exportações abertos por fator agregado (gráfico 4), o primeiro ponto que merece ser ressaltado é que somente em 1994, 1995 e 2004 houve aumento de preços tanto de básicos quanto de manufaturados e semimanufaturados. No restante do período, o movimento geral foi de queda, com destaque aos biênios 1992/93, 1998/99 e 2001/02 quando os três tipos sofreram perdas. A maior queda, entre 1992 e 2002, foi registrada nos produtos básicos (17\%) e a menor, nos manufaturados $(6,9 \%)$, que também apresentaram menor oscilação. A volatilidade dos preços de básicos e semi-manufaturados, em todo o período, foi duas vezes maior que a dos manufaturados, corroborando a preocupação com a perda de participação destes na pauta de exportações brasileiras.

Gráfico 4: Variação Percentual dos Preços das Exportações Brasileiras por Fator Agregado

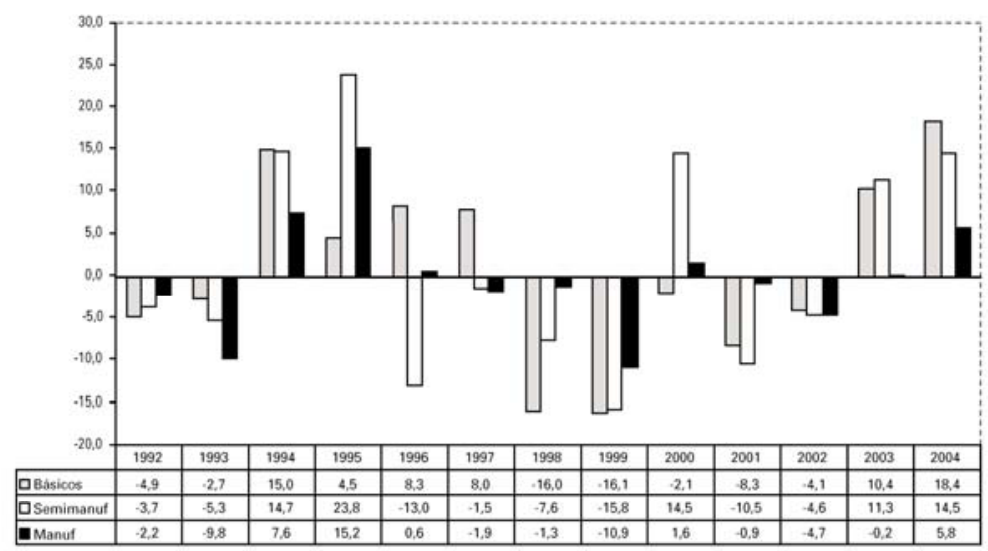

Fonte: FUNCEX 
Finalmente, no que tange a relação entre exportações e o grau de utilização da capacidade, podemos identificar três sub-períodos, destacados no gráfico 5: 1992-1994, 1995-2002 e 2003-2004. No primeiro deles há uma correlação positiva entre as variáveis, o contrário do esperado para o caso do Brasil, em que a exportação não é o principal fator do crescimento econômico, quando se analisa todo o período abordado nesse trabalho. No segundo, que compreende a maior parte do período analisado, a correlação foi negativa: as exportações parecem ter sido a alternativa para compensar o fraco desempenho econômico, refletido pelo acúmulo de capacidade ociosa na indústria. Por fim, no terceiro sub-período tem-se, novamente, uma correlação positiva entre as vendas externas e o nível de atividade da economia. No entanto, como ocorreu no primeiro sub-período, esse comportamento pode indicar uma relação apenas conjuntural, uma vez que, em 2005, ocorreria um arrefecimento do nível de atividade com um prosseguimento do crescimento das exportações.

Gráfico 5: Evolução das Exportações (1992 = 100) e da Utilização da Capacidade da Indústria

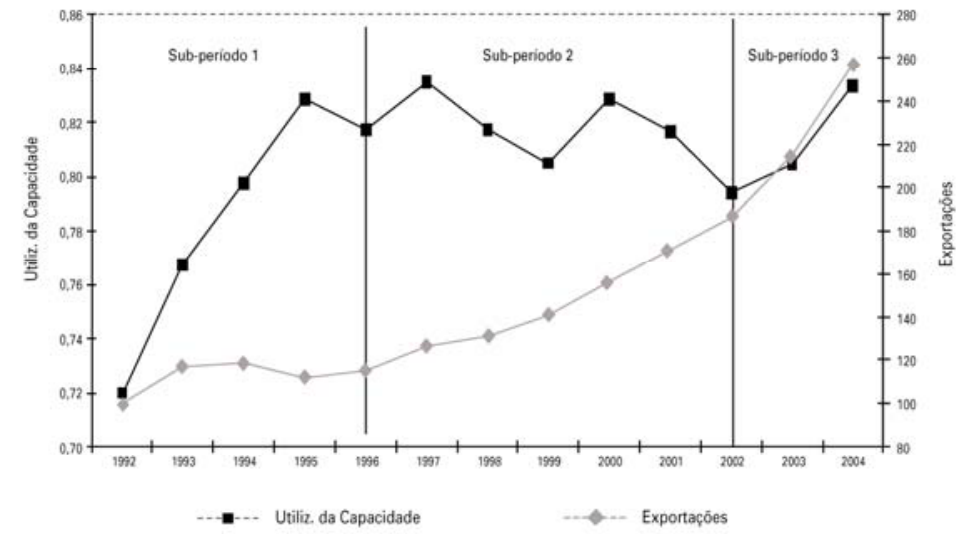

Fonte: Fundação Getúlio Vargas e Ministério do Desenvolvimento, Indústria e Comércio.

Após essa breve apresentação da dinâmica das exportações brasileiras entre 1992 e 2004, passaremos à descrição do exercício econométrico, iniciando com as fontes e o tratamento dos dados.

\section{FONTES E TRATAMENTOS DE DADOS}

Os dados de exportações estaduais anuais utilizados neste trabalho são do Ministério do Desenvolvimento, Indústria e Comércio Exterior (MDIC) e foram obtidos no site <http://aliceweb.desenvolvimento.gov.br.> Como deflator para os valores correntes em US\$ FOB, se utilizou o índice de preços das exportações por fator agregado da Fundação Centro de Estudos de Comércio Exterior (FUNCEX), disponível em www.ipeadata.gov.br. A cada parcela das pautas estaduais foi apli- 
cado o deflator correspondente, com o que se converteram os dados para valores constantes, em US\$ FOB, de 1998.

Para obter o câmbio real anual, específico por estado, partiu-se dos valores de câmbio real efetivo brasileiro do Núcleo de Conjuntura do Instituto de Economia da UFRJ, calculado a partir do INPC. Esses valores foram multiplicados pelos índices de preços de exportações estaduais, calculados a partir do índice de preços das exportações brasileiras da FUNCEX, e divididos pelo índice de preços internacionais ponderados pela pauta de exportações brasileiras, calculado com base em dados da OCDE, do FMI, do Ministério da Economia da Argentina e do Banco Central do Chile. A equação 1 sintetiza os procedimentos descritos acima:

(1) $E_{i t}=E_{i .}^{B R} \frac{P_{i t}^{\exp }}{P_{t}^{*}} \mathrm{i}=1, \ldots, 27, \mathrm{t}=1, \ldots, 13$,

onde:

$E_{i t}=$ câmbio real do estado $i$ no ano $t$;

$E_{t}^{B R}=$ câmbio real efetivo do Brasil no ano $t$;

$P_{i t}^{E X P}=$ índice de preço das exportações do estado $i$ no ano $t$;

$P_{t}^{*}=$ índice de preços internacionais no ano $t$.

A fonte dos dados de grau de utilização da capacidade instalada na indústria foi a Fundação Getúlio Vargas, e os valores anuais correntes em dólares $\mathrm{CIF}^{4}$ de importações mundiais utilizados são do IFS/FMI, deflacionados pelo índice de preços das importações mundiais (também do FMI).

\section{O MODELO}

A quantidade exportada por um país depende das condições de oferta e demanda de seus produtos. Pelo lado da oferta, os produtores decidem em qual mercado (interno ou externo) venderão sua produção com base no preço em moeda estrangeira, na taxa de câmbio, nos preços internos e no hiato do produto. Pelo lado da demanda, os condicionantes das decisões dos importadores de produtos nacionais são os preços em moeda estrangeira e a renda internacional. Têmse, portanto, as seguintes equações de oferta e demanda:

$$
\left\{\begin{array}{l}
\log X_{\$}^{S}=\beta_{o}^{S}+\beta_{1}^{S} \log \left(E .^{*} / P\right)+\beta_{2}^{S} \log H \\
\log X_{\$}^{D}=\beta_{o}^{D}+\beta_{1}^{D} \log P^{*}+\beta_{2}^{D} \log Y^{*} \\
\log X_{\$}^{S}=\log X_{\$}^{D}
\end{array}\right.
$$

${ }^{4} \mathrm{CIF}$ - Cost insurance and freight; modalidade em que o vendedor assume todos os custos referentes ao transporte, incluindo o seguro. 
onde $X_{\$}^{S}$ e $X_{\$}^{D}$ são, respectivamente os valores (em moeda estrangeira) ofertados e demandados, $E$ é a taxa de câmbio nominal, $P$ são os preços internos, $P^{*}$ o preço em moeda estrangeira, $H$ o hiato do produto e $Y^{*}$ a renda internacional. A terceira equação do sistema é a condição de equilíbrio, que estabelece igualdade entre oferta e demanda de exportações. ${ }^{5}$ A partir das três equações, derivamos uma única equação para as exportações (em quantum):

$$
\text { (2) } \log X=\alpha_{0}+\alpha_{1} \log \left(E P^{*} / P\right)+\alpha_{2} \log H+\alpha_{3} \log Y^{*}
$$

Ressalte-se que em (2) há somente fatores conjunturais como determinantes das exportações. A influência de variáveis estruturais é captada pelo intercepto e pelo erro.

\section{Exercício econométrico}

O objetivo do exercício econométrico foi calcular as elasticidades preço e renda das exportações dos estados brasileiros. Para isso, utilizou-se o câmbio real por estado (obtido conforme descrito na seção anterior) e, como proxy da renda internacional, as importações mundiais. Optou-se por trabalhar com essa aproximação dada a maior volatilidade do comércio internacional vis-à-vis à da renda, o que torna mais adequado incluir no modelo uma variável de comércio (as importações).

O método escolhido foi "Dados em Painel", o mais adequado diante da proposta de trabalhar com informações de 13 anos dos 27 estados brasileiros, os quais são o corte do modelo (cross-section).

Antes de apresentar o modelo, é importante discutir uma questão que costuma aparecer em estimativas em Painel. Ao escolher como modelar o intercepto, pode-se optar por: i) intercepto comum (um mesmo valor para todos os crosssection); ii) intercepto com efeito fixo (valores diferentes para cada cross-section); e iii) intercepto com efeito aleatório (uma parte comum e outra aleatória). A opção neste trabalho foi utilizar, alternadamente, intercepto comum e com efeito fixo. Como temos no cross-section toda a população de estados, faz sentido considerar o intercepto como um parâmetro a ser estimado (para cada estado ou, se for o caso, um mesmo para todos eles) e não como uma variável aleatória (o que se justificaria apenas no caso de extrações aleatórias de uma população muito grande) (Wooltridge, 2001).

No primeiro modelo estimado temos regressores com coeficientes comuns entre os estados $\left(i_{\mathcal{S}}\right)$ e intercepto com efeito fixo:

\footnotetext{
${ }^{5}$ Migon (2000) formula um modelo para as exportações de manufaturados em que incorpora basicamente as mesmas variáveis explicativas do presente trabalho. Porém, utiliza uma estrutura bayesiana para estimar as distribuições dos parâmetros.
} 
(3) $\log X_{i, t}=\beta_{0, i}+\beta_{1} \log E_{i, t}+\beta_{2} \log M_{1}+\beta_{3} C A P_{1}+\varepsilon_{i, t}$ (modelo 1)

$X_{i, t}=$ exportações do estado $i$ no ano $t$;

$E_{i, t}=$ taxa de câmbio real do estado $i$ no ano $t$,

$M_{t}=$ importações mundiais no ano $t$,

$C A P=$ utilização da capacidade instalada na indústria no ano $t$.

No segundo modelo, optou-se por decompor as importações mundiais, analisando-se o comportamento de sua tendência e do componente que agrega ciclos e choques (apresentados no gráfico 6). A decomposição foi feita com o filtro Hodrick-Prescott (HP), que nos fornece a estimação da tendência de longo prazo.

Gráfico 6: Importações Mundiais: Total, Tendência, Ciclo/Choque (em US\$ trilhões FOB de 1998)

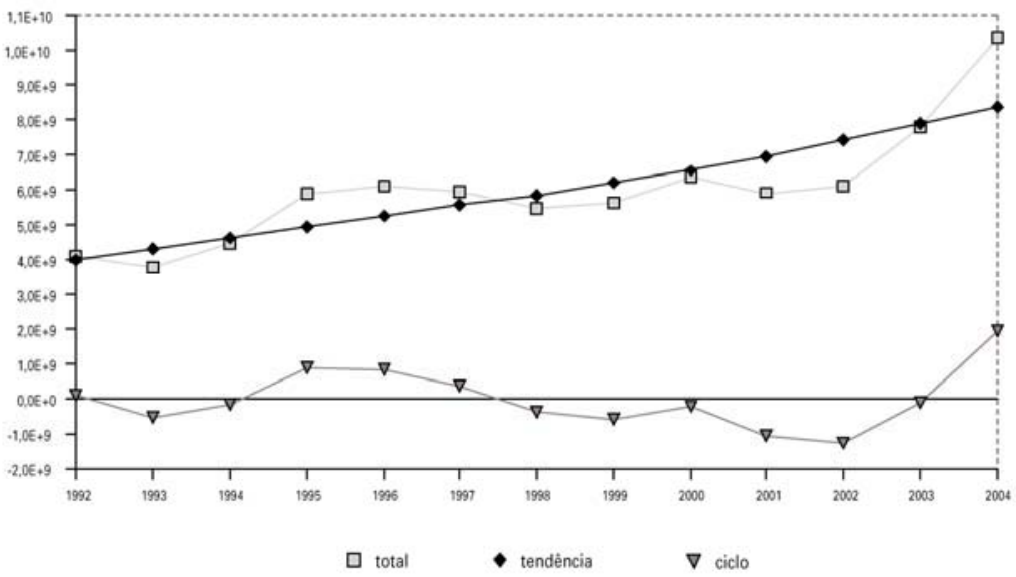

Fonte: Dados originais do IFS/FMI.

Pode-se observar, no gráfico 6, que o componente tendencial representa a maior parte do total das importações mundiais (as maiores participações atingidas pelos ciclos foram $15,72 \%$, em 1995, e 19,02\%, em 2004). Uma vez que a participação das exportações brasileiras no total das importações mundiais não chegou a $1 \%$ no período analisado, e dado o baixo dinamismo de nossa pauta, é esperado que as vendas externas do país não respondam ao ciclo das compras internacionais, hipótese que será testada na próxima seção.

Partindo da hipótese de que o componente cíclico não explica as variações das exportações brasileiras, na especificação do segundo modelo, o logaritmo das importações mundiais foi substituído pelo de sua tendência. Além disso, modificou-se o intercepto (que passou a ser comum) e o coeficiente do câmbio (agora específico para cada estado): 
(4) $\log X_{i, t}=\beta_{0}+\beta_{i, 1} \log E_{i, t}+\beta_{2} \log$ trend $_{1}+\beta_{3} C A P_{1}+\varepsilon_{i, t}$ (modelo 2)

Após essa exposição dos modelos econométricos, passamos agora à exposição e análise dos resultados.

\section{RESULTADOS}

As estimativas dos parâmetros do primeiro modelo foram obtidas através de Mínimos Quadrados Ordinários em Painel, e os valores calculados para a estatística $t$-student estão entre parênteses:

(5) $\log X_{i}=\hat{\beta}_{0, i}+1,01 \cdot \log E_{i, t}+0,65 \cdot \log M_{t}-1,48 . C A P_{t}$
$(3,92)$
$(2,28)$
$(-0,95)$

Os valores dos interceptos para cada estado estão relacionados na tabela 2.

Tabela 2: Estimativas do intercepto do modelo 1

\begin{tabular}{|lr|lr|lr|}
\hline AC & $-10,82$ & MA & $-5,2$ & RJ & $-3,9$ \\
\hline AL & $-5,98$ & MT & $-4,86$ & RN & $-6,7$ \\
\hline AP & $-7,95$ & MS & $-5,88$ & RS & $-2,94$ \\
\hline AM & $-5,8$ & MG & $-2,86$ & RO & $-7,81$ \\
\hline BA & $-4,05$ & PA & $-3,92$ & RR & $-10,26$ \\
\hline CE & $-5,59$ & PB & $-7,11$ & SC & $-3,69$ \\
\hline DF & $-9,72$ & PR & $-3,25$ & SP & $-1,84$ \\
\hline ES & $-3,83$ & PE & $-5,76$ & SE & $-8,13$ \\
\hline GO & $-5,48$ & PI & $-7,61$ & TO & $-10,12$ \\
\hline
\end{tabular}

Os valores encontrados para o $R$ quadrado, estatísticas $F$ e Durbin-Watson foram, respectivamente, $0,95,228,04$ e 1,08, indicando que o modelo de regressão é representativo, pois é capaz de explicar 95\% das variações das exportações e pelo menos um dos regressores é significativo (resultado do teste $F$ ). Como a estatística de Durbin-Watson (DW) indica possível problema de autocorrelação de resíduos, ${ }^{6}$ a correção será feita a seguir, com a introdução de um componente auto-regressivo.

6) $\log X_{i}=\hat{\beta}_{0, i}+0,53 \cdot \log E_{i, t}+0,83 \cdot \log M_{t}-9,13 . C A P_{t}+0,45 A R(1)$

Os valores dos interceptos para cada estado estão relacionados na tabela 3.

\footnotetext{
${ }^{6}$ Durbin-Watson menor que 2 indica a possibilidade de autocorrelação dos resíduos, porém, sendo seu valor maior que o de $R$ quadrado, não garante que exista de fato a autocorrelação. Ainda assim, optamos por fazer a correção, introduzindo o componente $A R(1)$ no modelo.
} 
Tabela 3: Estimativas do intercepto do modelo 1, com introdução de componente auto-regressivo no resíduo

\begin{tabular}{|lr|lr|lr|}
\hline AC & $-6,02$ & MA & $-0,4$ & RJ & 0,87 \\
\hline AL & $-1,23$ & MT & 0,04 & RN & $-1,84$ \\
\hline AP & $-3,04$ & MS & $-1,07$ & RS & 1,81 \\
\hline AM & $-0,92$ & MG & 1,89 & RO & $-2,9$ \\
\hline BA & 0,72 & PA & 0,83 & RR & $-5,55$ \\
\hline CE & $-0,83$ & PB & $-2,32$ & SC & 1,08 \\
\hline DF & $-5,04$ & PR & 1,58 & SP & 2,91 \\
\hline ES & 0,94 & PE & $-1,06$ & SE & $-3,49$ \\
\hline GO & $-0,63$ & PI & $-2,86$ & TO & $-4,83$ \\
\hline
\end{tabular}

Após a introdução do elemento auto-regressivo no erro, a estatística DW apresentou o valor de 2,13 (ou seja, o problema de auto-correlação foi corrigido). $O R^{2}(0,97)$ e a estatística $F(280,80)$ continuaram a ser satisfatórios.

Porém, foi constatada a presença de heterocedasticidade entre os cross-section, o que se explica pelo fato de os estados terem pautas e dinâmica de exportação muito diferentes. Realizaram-se três testes: Bartlett, Levene, e Brown-Forsythe e em apenas um deles não se rejeitou a hipótese nula de igualdade de variâncias (tabela 4).

Tabela 4: Testes de igualdade de variância no modelo 1 corrigido

\begin{tabular}{lcc}
\hline \multicolumn{1}{c}{ Método } & Estatísitca & Probabilidade \\
\hline Bartlett & 34,82 & 0,12 \\
\hline Levene & 2,34 & 0,00 \\
\hline Brown-Forsythe & 1,54 & 0,05 \\
\hline
\end{tabular}

O comportamento extremamente diverso dos resíduos de alguns estados representativos selecionados (e suas respectivas variâncias) pode ser constatado no gráfico 7.

Gráfico 7: resíduos de estados selecionados (modelo 1)

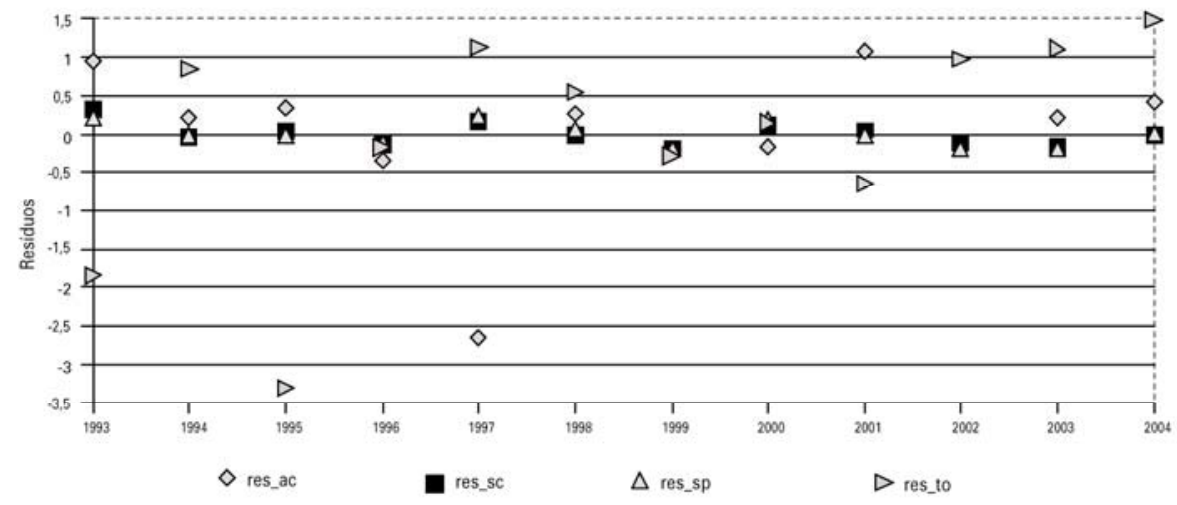


Tendo em vista a existência de heterocedasticidade, recorreu-se ao método de White, que utiliza um estimador da matriz de covariância consistente na presença de heterocedasticidade, possibilitando boas estimativas dos desvios padrões, utilizados na estatística $t$.

A estimativa do modelo com a correção de White resultou nos mesmos valores para os coeficientes, porém agora com maior significância de câmbio e importações. Note-se, por exemplo, que a estatística $t$ do coeficiente do câmbio passou de 2,22 para 2,76.

$$
\text { (7) } \log X_{i}=\hat{\beta}_{0, i}+0,53 \cdot \log E_{i, t}+0,83 \cdot \log M_{t}-9,13 \cdot C A P_{t}+0,45 A R(1)
$$

Os valores estimados para os interceptos também se mantiveram iguais, conforme mostra a tabela 5:

Tabela 5: Estimativas (método de White) do intercepto do modelo 1, com $A R(1)$

\begin{tabular}{|lr|rr|lr|}
\hline AC & $-6,02$ & MA & $-0,4$ & RJ & 0,87 \\
\hline AL & $-1,23$ & MT & 0,04 & RN & $-1,84$ \\
\hline AP & $-3,04$ & MS & $-1,07$ & RS & 1,81 \\
\hline AM & $-0,92$ & MG & 1,89 & RO & $-2,9$ \\
\hline BA & 0,72 & PA & 0,83 & RR & $-5,55$ \\
\hline CE & $-0,83$ & PB & $-2,32$ & SC & 1,08 \\
\hline DF & $-5,04$ & PR & 1,58 & SP & 2,91 \\
\hline ES & 0,94 & PE & $-1,06$ & SE & $-3,49$ \\
\hline GO & $-0,63$ & PI & $-2,86$ & TO & $-4,83$ \\
\hline
\end{tabular}

As estatísticas de avaliação da regressão foram: $R$ quadrado de 0,96 , estatística $F$ de 280,80 e DW de 2,13 (os mesmos valores encontrados anteriormente).

Antes de estimar os parâmetros do segundo modelo, foi feita a regressão da variação do $l o g$ das exportações contra a variação do $l o g$ das importações mundiais (para testar o componente cíclico como variável explicativa). O resultado foi a não-significância (ao nível de 10\%) desse elemento:

(8) $\Delta\left(\log X_{i, t}\right)=0,084-0,057 \Delta\left(\log M_{t}\right)$

$$
(8,88) \quad(-0,91)
$$

A estatística $t$-student para o coeficiente da variação do log das importações indicou que ele é não-significativo: a variação das exportações não responde às variações cíclicas das importações internacionais. Sendo assim, se optou por trabalhar com a tendência das importações mundiais (extraída pelo filtro HP). Dessa forma, se estimou a seguinte equação:

(9) $\log X_{i,}=\hat{\beta}_{0, i}+0,46 \cdot \log E_{i, t}+1,29 \cdot \log \left(\right.$ trendM $\left._{t}\right)-3,79 C A P_{t}+0,48 A R(1)$
$(3,75)$
$(-2,09)$
$(5,41)$ 
A principal mudança encontrada foi a elevação do coeficiente das importações (agora "tendência das importações"), o que confirma o esperado: ao se extrair o componente cíclico (que, conforme explicado acima, não explica as variações nas exportações brasileiras) se encontrou um valor maior para a elasticidade-renda (coeficiente $\beta_{2}$ ). Entretanto, ao se restringir a amostra para o período 1992-2001 esse coeficiente volta a ser menor que um, evidenciando uma mudança na resposta das exportações brasileiras à dinâmica do comércio mundial nos últimos anos. Naturalmente, interessaria avaliar se essa mudança tem caráter estrutural ou meramente conjuntural. Embora essa investigação extrapole o escopo do presente trabalho, pode ser mencionado que um bom ponto de partida para ela é verificar o que ocorreu com as exportações dos demais emergentes no período (sofreram forte crescimento, como no Brasil) ${ }^{7}$ e o que vem ocorrendo com a composição da pauta exportadora brasileira recentemente (um aumento na participação de produtos básicos e queda na de manufaturados).

O passo seguinte é a abertura do coeficiente do câmbio por estado (modelo 2), para o que foram encontrados os seguintes resultados:

(10) $\log X_{i,}=-16,58+\hat{\beta}_{1, i} \cdot \log E_{i, t}+1,32 \cdot \log \left(\right.$ trend $\left.M_{t}\right)-3,38 C A P_{t}+0,52 A R(1)$

$$
(-2,04) \quad(3,35) \quad(-1,78)
$$

Nesse modelo, ao nível de significância de $10 \%$, as estimativas do intercepto e dos coeficientes da tendência, da utilização da capacidade e do componente auto-regressivo são significativas. Os sinais dos parâmetros estimados foram os esperados: positivo para a tendência, retratando a trajetória de crescimento no período sob estudo; e negativo para a utilização da capacidade, o que corrobora a impressão de que, no Brasil do período analisado, as exportações representavam, em grande medida, uma alternativa de escoamento da produção em momentos de baixo dinamismo da economia nacional.

O valor de $-3,38$ do coeficiente da utilização da capacidade sugere que a um aumento de 1 ponto percentual na variável CAP, corresponde uma queda três vezes maior nas exportações. ${ }^{8} \mathrm{O}$ coeficiente do termo auto-regressivo sugere que parcela significativa $(52 \%)$ do comportamento das exportações tem relação com seu desempenho passado, o que pode estar relacionado ao padrão de formação de expectativas ou às safras agrícolas, entre outros fatores. Finalmente, o valor de 1,32 do coeficiente do $\log$ da tendência ${ }^{9}$ indica que a uma variação de $1 \%$ nes-

\footnotetext{
${ }^{7}$ Ver Boletim Política Econômica em Foco ${ }^{\circ} 5$ e WTO (2005).

${ }^{8}$ Note-se que, por termos a variável CAP em percentual e o $\log$ das exportações como variável explicada, o coeficiente $\beta_{3}$ representa uma elasticidade.

${ }^{9}$ É importante enfatizar que o valor de 1,32 não pode ser entendido como a elasticidade renda das exportações brasileiras totais, pois, dado o método de estimativa, está fortemente influenciado pela alta participação de São Paulo (estado com elevada parcela de manufaturados em sua pauta) no crosssection, o que significa que provavelmente a elasticidade do Brasil deve ser menor (Cavalcantti e Castro, 1997, por exemplo, encontraram um valor de 0,648 para a elasticidade de importações).
} 
ta, corresponde uma mudança de $1,32 \%$ nas exportações, o que contradiz a hipótese de que as vendas externas do país são inelásticas às importações mundiais (lembrando que estas estão sendo usadas como proxy para a renda externa). É importante enfatizar, contudo, que esse resultado considera apenas o componente tendencial, sendo possível, portanto, que se tenha inelasticidade em relação ao total das importações mundiais, como sugerido pela equação (6) (note-se que, mais uma vez, quando a amostra foi restringida ao período 1992-2001, se encontrou inelasticidade à tendência das importações, com um valor de 0,84$){ }^{10}$

As estimativas do coeficiente do câmbio estão relacionadas na tabela a seguir:

Tabela 6: Estimativas das elasticidades de câmbio do modelo 2

\begin{tabular}{|c|c|c|c|c|c|c|c|c|}
\hline & \multicolumn{2}{|c|}{ estat. $t$} & & \multicolumn{2}{|c|}{ estat. $t$} & & \multicolumn{2}{|c|}{ estat. $t$} \\
\hline AC & $-0,671$ & $-2,472$ & MA & 0,483 & 1,753 & RJ & 0,707 & 2,530 \\
\hline$A L$ & 0,326 & 1,169 & MT & 0,521 & 1,862 & RN & 0,141 & 0,505 \\
\hline AP & 0,009 & 0,030 & MS & 0,339 & 1,222 & $\mathrm{RS}$ & 0,933 & 3,351 \\
\hline AM & 0,327 & 1,150 & MG & 0,955 & 3,440 & $\mathrm{RO}$ & $-0,053$ & $-0,190$ \\
\hline BA & 0,700 & 2,522 & PA & 0,736 & 2,656 & RR & $-0,546$ & $-1,959$ \\
\hline $\mathrm{CE}$ & 0,386 & 1,390 & PB & 0,081 & 0,290 & SC & 0,785 & 2,823 \\
\hline DF & $-0,528$ & $-1,822$ & PR & 0,871 & 3,132 & SP & 1,159 & 4,162 \\
\hline ES & 0,755 & 2,734 & PE & 0,368 & 1,315 & SE & $-0,134$ & $-0,478$ \\
\hline $\mathrm{GO}$ & 0,398 & 1,426 & $\mathrm{PI}$ & 0,003 & 0,012 & TO & $-0,585$ & $-1,761$ \\
\hline
\end{tabular}

No que diz respeito às elasticidades preço (câmbio) estimadas (tabela 6), aceitamos somente os coeficientes dos maiores estados exportadores (BA, ES, MG, PA, PR, RJ, RS, SC, SP), embora o teste $t$ tenha sugerido que os de outros estados (AC, DF, RR) também são significativos a $10 \%$. A opção por não os aceitar se deveu ao seu sinal (negativo), indicando uma relação espúria com a variável câmbio. Chegou-se a essa conclusão devido à pequena participação de cada um desses estados no total da pauta exportadora brasileira e à extrema volatilidade que suas vendas externas apresentam - além das demais variáveis incorporadas no modelo (importações mundiais e utilização da capacidade), outros fatores, mais ligados à estrutura e à dinâmica das economias locais, parecem ser os determinantes principais de seu desempenho exportador, e não a variável conjuntural de preços (câmbio). Uma ilustração é dada pelo caso do Acre (gráfico 8), cujas exportações no período flutuaram ao redor de um patamar estável (pelo menos até 2002, quando as exportações não só do Acre, mas do país como um todo, começaram a crescer aceleradamente), ou seja, seu comportamento foi explicado basicamente pelo componente de ciclos e choques.

\footnotetext{
${ }^{10}$ Optou-se por não abrir o coeficiente das importações mundiais por dois motivos: (i) se tivermos na mesma equação $\beta_{1}$ e $\beta_{2}$ abertos por estado, há perda de muitos graus de liberdade, o que compromete a qualidade dos resultados encontrados; (ii) por outro lado, quando estimou-se $\beta_{2}$ por estado e um $\beta_{1}$ único, os resultados obtidos não foram robustos.
} 
Gráfico 8: Exportações do Acre: total, tendência, ciclo/choque (em US\$ mil FOB de 1998)

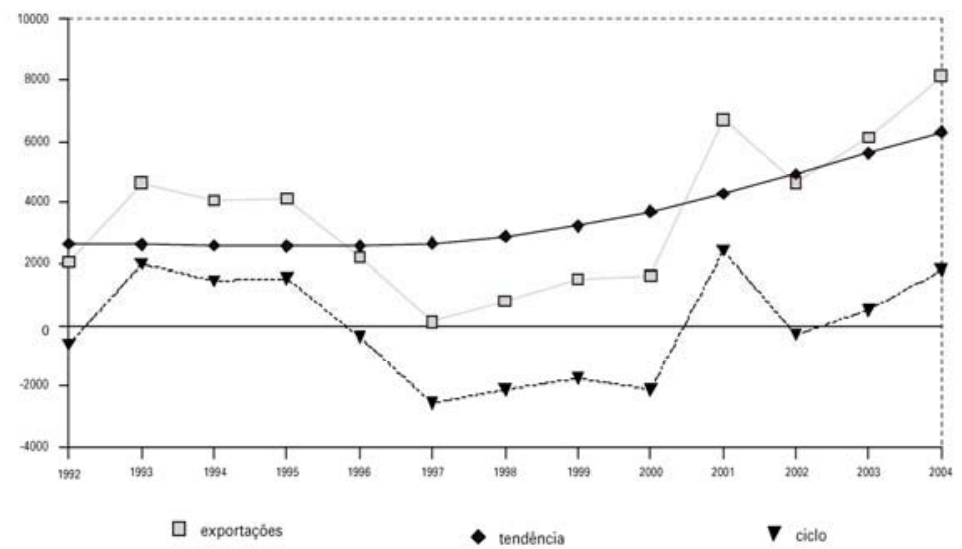

Ressalte-se que a elasticidade câmbio de São Paulo é bem maior que a dos demais estados, o que se explica pela alta participação de manufaturados em sua pauta, os quais representavam, em 2004, $82 \%$ do total exportado pelo estado. O Rio de Janeiro, por outro lado, conquanto fosse, em 2004, o quinto estado em quantum exportado (a preços constantes de 1998), possuía apenas a oitava maior elasticidade, o que provavelmente decorre da elevada especialização do estado em produtos básicos (que passaram de 0,8\%, em 1992, para 59,5\%, em 2004).

Por fim, as estatísticas de avaliação da regressão sugerem um bom ajuste do modelo, com valores de 0,97 para o $R$ quadrado, 202,51 para o teste $F$ e DW de 2,20.

\section{CONCLUSÃO}

As exportações brasileiras (a preços constantes) no período analisado apresentaram comportamentos variados, permitindo a delimitação de três sub-períodos. À relativa estabilidade nos primeiros anos, se seguiu um momento de queda e de lenta recuperação, após a mudança de regime econômico e a valorização da moeda nacional em 1994, para apenas após a desvalorização de 1999 retomarem trajetória de crescimento mais expressivo - puxada principalmente por produtos de menor valor agregado.

Esse desempenho parece, em grande medida, corroborar a tese de Coutinho (1997), de que o país passou na década de 90 por um processo de "especialização regressiva" no que tange as transações comerciais, tendo em vista a queda da participação de produtos de maior valor agregado na pauta exportadora. ${ }^{11}$

\footnotetext{
${ }^{11}$ Ressalve-se, entretanto, que o processo de especialização regressiva observado de fato foi mais brando do que previa o autor. Embora tenha havido um retrocesso na composição da pauta de exportação, o mesmo fato não ocorreu (ao menos não nas proporções previstas) com a indústria nacional.
} 
Note-se, porém, que, apesar de ser desejável uma alta participação de manufaturados na pauta, como as exportações de básicos têm um componente importado muito baixo, elas representam um ganho líquido em termos de saldo comercial, vis-à-vis aos manufaturados, cuja produção depende, em alguns casos, de vultosas quantidades de insumos importados (notadamente no setor de metalmecânica). ${ }^{12}$ Entretanto, embora esse argumento relativize a importância de se evitar um contínuo aumento da participação de básicos na pauta exportadora, ele não a elimina uma vez que elevações na participação de básicos tendem a reforçar o problema da dependência de produtos de baixo dinamismo.

Prebisch (1952) já havia ressaltado que a combinação entre exportações de baixa elasticidade e importações de alta elasticidade representava um sério problema às possibilidades de crescimento da economia nacional a longo prazo. Sendo assim, seria fundamental ao país não apenas exportar, mas, sobretudo, exportar produtos de altas elasticidades, que garantam a capacidade de importação, reduzindo o problema da restrição externa e, assim, permitindo o crescimento continuado.

No Brasil, a análise realizada neste trabalho sugere que o papel reservado às exportações seria não o de alavancar o crescimento doméstico, mas sim o de possibilitar a superação do problema da restrição externa. Entretanto, dada sua composição que lhes confere baixo dinamismo, elas não foram capazes de cumprir tal função - pelo menos não até 2004. Ainda que tenha apresentado comportamento anti-cíclico, o que está captado pelo coeficiente negativo encontrado para a utilização da capacidade, o desempenho do setor exportador não foi, quando considerado todo o período de análise, dinâmico o suficiente para permitir o crescimento sem a restrição de divisas. Obviamente, tendo em vista apenas os anos recentes, é possível que esse quadro esteja se revertendo e que o país esteja caminhando para um novo tipo de inserção externa. Entretanto, por enquanto não é possível fazer tal afirmação, pois há grande possibilidade de que o espetacular desempenho exportador dos últimos anos resulte somente de fatores conjunturais e não de uma nova e mais robusta dinâmica setorial.

Dentre os diversos estados, verificamos que apenas São Paulo, o estado cuja pauta possui a maior participação de produtos com alto valor agregado, apresentou dinâmica diferente da de regiões que exportam produtos de baixo valor agregado. Quanto aos demais, não parecem capazes de aproveitar proporcionalmente as vantagens derivadas das variações na renda do mercado consumidor e nos preços de seus produtos, o que se traduz em elasticidades de câmbio, para todos os estados em que são significativas, menores do que 1.

Ainda assim, cabe assinalar o comportamento diferenciado dos estados no que tange as mudanças na composição de suas pautas. Minas Gerais, o segundo estado em quantum exportado (em 2004), experimentou um processo de intensa regressão (no sentido dado por Coutinho), com a participação de manufaturados

${ }^{12}$ Para maiores detalhes, consultar Markwald (2001). 
despencando de 45\%, em 1992, para 35\%, em 2004. Paraná, por outro lado, viveu um processo inverso: suas exportações quadruplicaram no período, sendo puxadas por manufaturados e, em menor grau, semi-manufaturados, com queda na participação de básicos (de $51 \%$ para $42 \%$ ). As vendas externas do estado eram, em 1992, mais de 50\% menores que as do Rio Grande do Sul (o terceiro estado exportador). Já em 2004, eram apenas 4\% menores. Quando a esses fatos combinamos a queda de participação de manufaturados nas exportações gaúchas (o que, entretanto, não impediu o estado de, em quantum exportado, se aproximar de Minas Gerais), podemos esperar uma elevação relativa nas elasticidades paranaenses: ao contrário do RS e de MG, o PR experimentou um movimento de dinamização da pauta, isto é, suas exportações não apenas cresceram vigorosamente como também passaram a ser compostas por produtos de maior valor agregado.

Finalmente, verificamos que as exportações no período da análise apenas seguiram a tendência das importações mundiais, e não seu ciclo. Contudo, ao contrário do que se esperava a princípio, se constatou uma resposta elástica de nossas exportações à dinâmica da renda mundial, ao menos quando considerado seu componente tendencial. De todo modo, quando se considera a dinâmica de cada um dos estados exportadores em separado, tudo indica que a elasticidade agregada é, em grande medida, resultante do dinamismo do comércio exterior paulista nos anos recentes (lembrar que, para a amostra restrita a 1992-2001, se observou inelasticidade) e não tanto dos demais estados (vale lembrar, novamente, o resultado encontrado na equação 6). Isso é um possível reflexo da pequena participação na pauta brasileira de produtos de "demanda crescente" no comércio mundial. ${ }^{13}$ De acordo com estudo do IEDI (2003), apenas $26 \%$ dos produtos brasileiros estavam, entre 1998 e 2001, na categoria de "demanda crescente", o pior índice dentre todos os países do estudo, bem abaixo dos 53\% da África do Sul, os $42 \%$ da China e dos $43 \%$ do mundo. Mesmo o Chile, um país com baixa participação de manufaturados no total exportado, tinha $28 \%$ das exportações em produtos de "demanda crescente". Outros dois estudos, também do IEDI (2005a, $2005 b$ ), indicam que as mega-exportações dos últimos anos têm origem em setores de baixo conteúdo tecnológico e reduzido dinamismo internacional, o que reforça as suspeitas de melhorias apenas conjunturais, passíveis de rápida reversão se a economia doméstica voltar a apresentar crescimento expressivo ou se a demanda internacional arrefecer.

Diante das limitações e fragilidades da inserção exportadora brasileira apontadas neste trabalho, surge, de forma natural, a questão: como se comportariam as vendas do país se a economia voltasse a apresentar crescimento contínuo a taxas expressivas? Nossas observações para o período de 1992 a 2004 permitem imaginarmos que, a não ser que ocorra uma forte desvalorização do real, uma

\footnotetext{
${ }^{13}$ Por produtos de "demanda crescente" entendam-se aqueles cujas exportações em valor aumentaram como percentual do total das exportações mundiais.
} 
retomada vigorosa do crescimento terá como contrapartida a elevação da fragilidade externa, visto que as exportações não deverão ter dinamismo suficiente para fazer frente ao aumento expressivo das importações exigido pelo crescimento.

\section{REFERÊNCIAS BIBLIOGRÁFICAS}

CAVALCANTI, M. A. e CASTRO, A. S. "Estimação de Equações de Exportação e Importação para o Brasil - 1955/95”, Texto para Discussão IPEA, n 469, 1997. Disponível em: www.ipea.gov.br.

CAVALCANTI, M. A. e RIBEIRO, J. F. “As exportações brasileiras no período 1977-96: desempenho e determinantes", Texto para Discussão IPEA, $\mathrm{n}^{\circ}$ 545, 1998. Disponível em: www.ipea.gov.br.

COUTINHO, L. G. "A Especialização Regressiva: Um Balanço do Desempenho Industrial Pós-Estabilização”, in: Velloso, J.P.R. (org.) Brasil: Desafios de um País em Transformação, Rio de Janeiro: José Olympio, pp. 81-106, 1997.

Developing Countries' Goods trade Share Surges to 50-year Peak. In: World Trade Organization WTO - Press Releases - 14/04/2005. Disponível em: www.eto.org. Retirado em: janeiro de 2005.

IEDI. Aspectos Relacionados ao Dinamismo e à Tecnologia no Comércio Exterior Brasileiro - O Primeiro Semestre de 2005, 2005b. Disponível em: www.iedi.org.br. Acesso em: dezembro de 2005.

IEDI. O Comércio Exterior Brasileiro em 2004, 2005a. Disponível em: www.iedi.org.br. Acesso em: dezembro de 2005.

IEDI. Radiografia das Exportações, 2003. Disponível em: www.iedi.org.br. Acesso em: março de 2004.

KRUGMAN, P. R. e OBSTFELD, M. Economia Internacional - Teoria e Política, 5 ed., São Paulo: Makron Books, 2001.

MARKWALD, R. "O Impacto da Abertura Comercial sobre a Indústria Brasileira”, in: Velloso, J.P.R. (coord.), Como vão o Desenvolvimento e a Democracia no Brasil”, Rio de Janeiro: José Opympio, 2001.

MEDEIROS, C. e SERRANO, F. Inserção Externa, Exportações e Crescimento no Brasil, mimeo. Disponível em: www.ie.ufrj.br. Acesso em: março de 2004.

MIGON, H. S. "The Prediction of Brazilian Exports Using Bayesian Forecasting”, Investigacion Operativa, vol. 9, n 1, 2, 3, março-julho, 2000.

Política Econômica em Foco $n^{\circ} 5$ - Novembro de 2004 a Abril de 2005. Instituto de Economia da UNICAMP. Disponível em: www.eco.unicamp.br. Acesso em: janeiro de 2005.

PREBISCH, R. "Problemas Teóricos e Práticos do Crescimento Econômico", Bielschowsky, R. (ORG) 50 Anos e Pensamento na CEPAL, 2000. Primeira edição em espanhol: 1952.

WOOLTRIDGE, J.M. Econometrics Analysis of Cross-Section and Panel Data, Cambridge, MIT Press, 2001.

WTO, Developing Countries Goods Trade Share Surges to 50-year peak, 2005, press releases. 